Revista Eletrônica de Direito Processual - REDP.

Rio de Janeiro. Ano 11. Volume 18. Número 1. Janeiro a Abril de 2017

Periódico Quadrimestral da Pós-Graduação Stricto Sensu em Direito Processual da UERJ

Patrono: José Carlos Barbosa Moreira. ISSN 1982-7636. pp. 302-324

www.redp.uerj.br

\title{
EFETIVIDADE DA TUTELA JURISDICIONAL E O DIREITO FUNDAMENTAL À PROVA NO NOVO CPC ${ }^{1}$
}

\section{JUDICIAL PROTECTION EFFECTIVENESS AND THE FUNDAMENTAL RIGHT TO PROOF IN THE NEW BRAZILIAN CIVIL PROCEDURE RULES}

Luis Alberto Reichelt

Mestre e Doutor em Direito pela UFRGS. Professor nos cursos de graduação, especialização, mestrado e doutorado em Direito da PUCRS. Procurador da Fazenda Nacional em Porto Alegre (RS).

luis.reichelt@pucrs.br

Guilherme Athayde Porto Especialista, Mestre e Doutorando em Direito Processual Civil pela PUCRS. Professor. Advogado.

guilherme@spud.adv.br

RESUMO: O presente estudo busca refletir sobre a efetividade do direito fundamental à prova à luz do Novo Código de Processo Civil, tomando como indicativos para tal aferição as noções de descoberta da verdade no processo e de livre convencimento motivado. Nesta mesma linha, aproveita-se para examinar a prova testemunhal com a introdução da possibilidade do cross-examination e também a prova pericial frente aos negócios processuais.

PALAVRAS-CHAVE: Processo Civil - prova - direito fundamental - efetividade.

ABSTRACT: The present study aims to reflect about the effectiveness of the fundamental right of proof considering the Civil Procedure Rules, taking as a measure the ideas of truth discovery through the process and of the rational persuasion. In this sense, it is examined the

\footnotetext{
${ }^{1}$ Artigo recebido em 05/01/2017 e aprovado em 27/03/2017.
} 
Revista Eletrônica de Direito Processual - REDP.

Rio de Janeiro. Ano 11. Volume 18. Número 1. Janeiro a Abril de 2017

Periódico Quadrimestral da Pós-Graduação Stricto Sensu em Direito Processual da UERJ

Patrono: José Carlos Barbosa Moreira. ISSN 1982-7636. pp. 302-324

www.redp.uerj.br

testimonial evidence with the introduction of the possibility of cross-examination and also the expert witness in the context of the procedural negotiation.

KEYWORDS: Civil Procedure - evidence - fundamental right - effectiveness.

SUMÁRIO: 1. Introdução. 2. Em busca de critérios para a aferição da efetividade do direito fundamental à prova. 2.1. Prova e descoberta da verdade. 2.2. Prova e livre convencimento motivado. 3. Questões sobre a efetividade do direito fundamental à prova no novo CPC. 3.1 O cross examination e a produção da prova oral. 3.2 A prova pericial sob a perspectiva dos negócios processuais - a eleição do perito e o calendário processual. 4. Conclusão. 5. Referências Bibliográficas.

\section{Introdução.}

Tratar sobre o direito probatório é enfrentar um dos mais caros assuntos associados à ciência processual. Com a entrada em vigor do novo Código de Processo Civil, o debate ganha novo fôlego, vez que existem alterações que devem ser analisadas de modo que se possa verificar a adequação do novo sistema proposto pelo legislador ao paradigma dos direitos fundamentais.

Neste sentido, propõe-se investigar a efetividade do direito fundamental à prova, propondo-se indicativos para sua aferição o debate sobre a relação entre prova e descoberta da verdade, bem como o impacto do conceito de livre convencimento motivado, refletindo sobre os termos em que se mostra possível afirmar sua permanência ou não no Código de Processo Civil. Por fim, entrando-se em temas mais pragmáticos, analisar-se-á o impacto da adoção do sistema do cross-examination nesse mesmo contexto, bem como será feita reflexão sobre a prova pericial e o calendário processual à luz dos negócios processuais.

\section{Em busca de critérios para a aferição da efetividade do direito fundamental à prova.}

Diversas são as concepções existentes a respeito da fundamentalidade do direito à prova. Nesse sentido, uma primeira abordagem é a que assim o trata como corolário natural do contraditório e da própria ampla defesa, vistos como forma de se atingir os ideais do novo processo civil, ainda mais quando se defende um processo justo e colaborativo. Nesse sentido, sintomática é a lição de Fredie Didier Jr., para quem “o direito à prova é conteúdo do direito fundamental ao contraditório. A dimensão substancial do princípio do 
Revista Eletrônica de Direito Processual - REDP.

Rio de Janeiro. Ano 11. Volume 18. Número 1. Janeiro a Abril de 2017

Periódico Quadrimestral da Pós-Graduação Stricto Sensu em Direito Processual da UERJ

Patrono: José Carlos Barbosa Moreira. ISSN 1982-7636. pp. 302-324

wWw.redp.uerj.br

contraditório o garante. Nesse sentido, o direito à prova é também um direito

fundamental",2.

A prova, em si, constitui-se em instituto essencial para a realização do Estado

Democrático de Direito, sendo fator indispensável à composição da ideia de um processo justo, impedindo, em face de sua essência, a tomada de decisões arbitrárias. Esse caráter instrumental associado à prova pode ser visto na lição de Hernando Devis Echandía, para quem "las pruebas son asi un instrumento elemental no tanto del processo como del derecho, y no tanto del proceso de conocimiento como del proceso en general: Sin ellas, en el noventa y nueve por ciento de las veces, el derecho no podria alcanzar su finalidad"3.

A compreensão da essência do fenômeno probatório pressupõe a reflexão a respeito da finalidade que lhe é associada e dos resultados que dele são esperados. Impõe-se nesse ponto, avançar mais detidamente.

\subsection{Prova e descoberta da verdade}

Um dos mais complexos temas no estudo do conteúdo do direito fundamental à prova é a relação entre prova e verdade, uma relação que enseja o surgimento de inúmeros questionamentos de ordem prática ${ }^{4}$.

\footnotetext{
${ }^{2}$ DIDIER JR, Fredie, BRAGA, Paulo Sarno, OLIVEIRA, Rafael Alexandria de. Curso de Direito Processual Civil. V. II. $10^{\mathrm{a}}$ ed. Salvador: Juspodivm, 2015, p. 41. No mesmo sentido, está a ideia de Antonio do Passo Cabral e Ronaldo Cramer: "A premissa que deve orientar toda análise da legislação infraconstitucional em matéria de provas é a de que constituem manifestação da garantia constitucional do acesso à justiça o direito à postulação probatória, o direito à produção das provas deferidas com respeito ao contraditório e o direito à valoração adequada do acervo probatório produzido" (CABRAL, Antonio do Passo, CRAMER, Ronaldo. Comentários ao Novo Código de Processo Civil. Rio de Janeiro: Forense, 2015. p. 572).

${ }^{3}$ ECHANDÍA, Hernando Devis. Compendio de la Prueba Judicial, Tomo I. Buenos Aires: Aguilar, 1981, p. 14. No mesmo sentido encontra-se a ideia de Carlo Furno, que afirma: "Tutto questo non breve discorso sarebbe stato senz'altro risparmiato se esso no agevolasse, a mio vedere, la comprensione di quel complesso fenomeno giuridico che siam soliti designare col nome di prova. Dico genericamente fenomeno giuridico di chiarire, la funzione della prova non si esaurire tutta soltanto nel processo, anche se il processo è il suo istituzione e costante punto di riferimento: e ciò há perfettamente compesso il Carnelutti, allorchè insegna che le prove 'sono... uno strumento elementare non tanto del processo quanto del diritto"' (FURNO, Carlo. Contributo Alla Teoria Della Prova Legale.. Padova: Cedam, 1940, p. 16-17.)

${ }^{4}$ Paradigmáticos, a esse respeito, os questionamentos formulados por Susan Haack: "Is truth in the law just plain truth - or something sui generis? Is a trial a search for truth - or is it something more, something less, than that? Do the adversarial procedures of common-law systems promote factually sound veridicts? Do legal rules excluding relevant testimony enable the accurate determination of factual issues, or impede it? What bearing, if any, does the mathematical calculus of probabilities have on the degree and standards of proof invoked in the law? What role can statistical evidence appropriately play in legal proof? How does the argument and counter-argument of adversarial proceeding differ from what scientists do as the seek out, sift, and weigh evidence? How can courts best handle the scientific testimony on which they now so often rely, and how are they to distinguish genuine Science from pretender - or reliable scientific testimony from unreliable hokum?"
} 
Revista Eletrônica de Direito Processual - REDP.

Rio de Janeiro. Ano 11. Volume 18. Número 1. Janeiro a Abril de 2017

Periódico Quadrimestral da Pós-Graduação Stricto Sensu em Direito Processual da UERJ

Patrono: José Carlos Barbosa Moreira. ISSN 1982-7636. pp. 302-324

www.redp.uerj.br

Não há dúvida de que a aproximação entre prova e verdade é, em última

instância, uma tentativa de traduzir o ideal de busca de justiça presente na atividade instrutória desenvolvida no debate processual. Nesse sentido, emblemática é a lição de Rui Manuel de Freitas Rangel ao anotar que "a verdade e a justiça são realidades e valores complementares. É nesta complementaridade que dentro da estrutura do processo a prova resultante da atividade probatória desenvolvida pelas partes, pelo juiz e por terceiros chega a uma determinada finalidade ou seja, a um certo resultado"5. Esse elo também pode ser visto, de certa forma, nas palavras de Michele Taruffo, para quem “a verificação da verdade dos fatos que dizem respeito ao caso concreto constitui apenas uma das condições para justiça da decisão, que para ser justa pressupõe também que tenha sido desenvolvido de modo correto e legítimo o processo da qual constitui o resultado final e - obviamente também venha interpretada corretamente a norma que o juiz adota como regra de juízo"6.

Esse liame pode ser visto, ainda, na lição de Luiz Guilherme Marinoni, Ingo Sarlet e Daniel Mitidiero, ao anotarem que "a verdade é pressuposto ético do processo justo. Uma das fontes de legitimação da função judiciária é a verdade - veritas, non auctoritas faci iudicium. É necessariamente injusta a decisão baseada em falsa verificação das alegações de fato no processo. Daí existir uma relação teleológica entre prova e verdadea prova visa à apuração da veracidade das alegações de fato”, esclarecendo, mais adiante, que, em sua concepção, "a verdade é um problema unitário - inexiste a possibilidade de separação entre verdade dentro e fora do processo - e pode ser satisfatoriamente definida a partir da ideia de correspondência",7.

Essa última ordem de considerações traz à tona a necessidade de aferição do grau de intensidade do compromisso da atividade de instrução com o objetivo de compreensão da verdade através da investigação desenvolvida nos autos. Sobre o ponto, anota Michele Taruffo que, "de fato, a ideia de uma verdade absoluta pode ser uma hipótese abstrata em um contexto filosófico amplo; entretanto, não se pode sustentar racionalmente

(HAACK, Susan. Evidence Matters - Science, Proof and Truth in the Law. Cambridge: Cambridge University Press, 2015. p. 15).

${ }^{5}$ RANGEL, Rui Manuel de Freitas. O ônus da prova no processo civil. Coimbra: Almedina, 2000, p.35.

${ }^{6}$ TARUFFO, Michele. Verdade e Processo. In: TARUFFO, Michele. Processo Civil Comparado: Ensaios. São Paulo: Marcial Pons, 2013. p. 36.

7 SARLET, Ingo Wolfgang; MARINONI, Luiz Guilherme; MITIDIERO, Daniel. Curso de Direito Constitucional. São Paulo: Revista dos Tribunais, 2012, p. 656. 
Revista Eletrônica de Direito Processual - REDP.

Rio de Janeiro. Ano 11. Volume 18. Número 1. Janeiro a Abril de 2017

Periódico Quadrimestral da Pós-Graduação Stricto Sensu em Direito Processual da UERJ

Patrono: José Carlos Barbosa Moreira. ISSN 1982-7636. pp. 302-324

www.redp.uerj.br

que uma verdade absoluta possa ou deva ser estabelecida em qualquer domínio de conhecimento humano, tampouco no contexto judicial"8.

Efetivamente, o conhecimento da realidade histórica através da investigação processual pode dar-se em maior ou menor intensidade. Entender que a noção de verdade funciona como um valor-limite ajuda a compreender o desenvolvimento do procedimento como forma de construção da conclusão, dimensionando-se o papel da prova como um dos elementos necessários para a decisão justa, inserido no contexto do necessário respeito ao devido processo constitucional. O emprego de standards de prova, sob essa ótica, é também um indicativo de que a formação do convencimento judicial envolve um grau de conhecimento suficiente da realidade que não necessariamente impõe que a prova retrate com exatidão absoluta o que se passou do ponto de vista histórico. A solução judicial, assim, mais das vezes, se colocará entre dois extremos, o do não conhecimento e o da verdade absoluta ${ }^{9}$.

Ainda que se reconheça a impossibilidade de chegada à verdade absoluta, ou que se opte por afirmar que a verdade absoluta possui valor apenas teórico para o processo, é necessário destacar que sua função vai além do mero ideal, funcionando como norte a ser perseguido na investigação dos autos. É como diz Calamandrei ao anotar que "anche se siamo convinti che la natura umana non è capace di raggiungere le verità assolute, è dovere di onesta adoprarsi con tutte le forze per cercare di approssimarsi quanto più si può alla meta irraggiungibile ${ }^{, 10}$.

A prova funciona nessa dimensão, como instrumento destinado à construção de um retrato possível da realidade, fazendo presentes diante dos olhos do julgador fatos que, muitas vezes, não mais existem. Pelo prisma dessa função retórica, a prova cível serve como ferramenta pela qual é trazida aos autos uma versão possível dessa mesma realidade, a qual pode ou não corresponder àquilo que efetivamente aconteceu, constituindo-se como

\footnotetext{
${ }^{8}$ TARUFFO, Michele. A Prova. São Paulo: Marcial Pons, 2014. p. 25.

9 Sobre o tema, valiosa é a lição de Michele Taruffo, pois refere que "mentre ad un estremo vi è la nonconoscenza, l'estremo oposto può essere rappresentato dalla verità assoluta: ciò che rimane è che essa è solo un punto di riferimento teórico, um valore tendenziale che non può essere concretamente realizzato $m$ ache tuttavia serve a determinare e a orientare i valori 'relativi' concreti. Un grado di conoscenza è un grado (ed è conoscenza relativa) in quanto si coloca in qualche punto intermedio tra la non-conoscenza e la conoscenza della verità assoluta di alcunché: esso si determina in positivo secondo la sua distanza dall'estremo della nonconoscenza e in negativo secondo la sua distanza dall'estremo della verità assoluta." (TARUFFO, Michele. La Prova dei Fatti Giuridici. Milano: Giufrè, 1992. p. 155).

${ }^{10}$ CALAMANDREI, Piero. Verità e Verosimiglianza Nel Proceso Civile. Rivista di Diritto Processuale, vol. XX (1955): 164-192, especialmente p. 191.
} 
Revista Eletrônica de Direito Processual - REDP.

Rio de Janeiro. Ano 11. Volume 18. Número 1. Janeiro a Abril de 2017

Periódico Quadrimestral da Pós-Graduação Stricto Sensu em Direito Processual da UERJ

Patrono: José Carlos Barbosa Moreira. ISSN 1982-7636. pp. 302-324

www.redp.uerj.br

esforço argumentativo situado no âmbito do contexto da descoberta ${ }^{11}$. Nesta senda, ainda que a produção da prova não se constitua em garantia de efetivo conhecimento da realidade histórica, o esforço narrativo realizado pelas partes para levar ao juiz sua versão do ocorrido muitas vezes acaba por culminar em uma reflexão a respeito da carga probatória como critério para que se possa decidir a respeito da veracidade ou não do que foi relatado. Não há como, então, ignorar que o conhecimento da verdade é uma situação-limite, funcionando a prova como ferramenta que legitima a convicção do juiz, a quem compete não a tarefa de investigar a história a qualquer preço, mas sim a de proferir uma decisão ${ }^{12}$.

Com esses pilares, escancarada está a importância de associar ao juiz um papel ativo e não apenas reativo, de modo que ele se junte às partes em uma estrutura de verdadeira colaboração com vistas à construção da decisão judicail. Neste viés, é autorizado o magistrado a determinar a produção de provas e tomar outras medidas que entender necessárias para conduzir a atividade de instrução de maneira efetiva. O papel do juiz, como verdadeiro defensor do respeito à ordem jurídica, somente é devidamente cumprido na medida em que o seu agir seja capaz de implementar o desenvolvimento de um processo justo.

A atualidade do debate ora proposto pode ser ilustrada através do olhar em direção ao intenso debate travado entre Bruno Cavallone e Michele Taruffo a respeito das relações entre prova e verdade. Lançando mão da ideia de "verifobia", Cavallonne sustenta uma linha de pensamento segundo a qual o conhecimento da verdade seria inatingível, e, portanto, irrelevante para o processo. Conforme o autor citado, "alla base dell'idea di una giustizia (puramente) procedurale, del resto, da un lato starebbe 'la rinuncia, consapevole o inconsapevole, ad elaborare anche qualche concetto di giustizia sostanziale', dall'altro 'l'adesione più o meno esplicita alla concezione del processo secondo la quale esso sarebbe orientato esclusivamente allá risoluzione delle controversie'”.' Segundo o citado autor, não há correspondência necessária entre as ideias de solução de uma controvérsia e de justiça em uma decisão judicial, o mesmo valendo a respeito da determinação da verdade dos fatos. A investigação da verdade, para Cavallone, não guarda qualquer relação com a função ritual

\footnotetext{
${ }^{11}$ A esse respeito, ver REICHELT, Luis Alberto. A Prova no Direito Processual Civil. Porto Alegre: Livraria do Advogado, 2009. p.151-152.

${ }^{12}$ Conforme anota Piero Calamandrei, "Il giudice non è permesso, come allo storico, restare incerto sui fatti da decidere; egli deve ad ogni costo (questa è la sua funzione) risolvere la controvérsia in una certeza giuridica.” (CALAMANDREI, Piero. Verità e Verosimiglianza Nel Proceso Civile. Op. cit., p. 165)
} 
Revista Eletrônica de Direito Processual - REDP.

Rio de Janeiro. Ano 11. Volume 18. Número 1. Janeiro a Abril de 2017

Periódico Quadrimestral da Pós-Graduação Stricto Sensu em Direito Processual da UERJ

Patrono: José Carlos Barbosa Moreira. ISSN 1982-7636. pp. 302-324

www.redp.uerj.br

do processo, anotando que a identificação entre uma "boa justiça" e a prolação de uma decisão "verdadeira" importaria em distanciar a própria ideia de "ofertar justiça” em relação ao contexto humano e social no qual essa atuação se insere, que é "necessariamente limitato, imperfetto, pragmático", deixando o juiz em uma escalada transcendental rumo a um "sapere infinito"13. Em contraponto a tais ideias, combatendo a "verifobia", Michele Taruffo defende que a norma só pode ser corretamente aplicada quando os fatos forem declarados verdadeiros ${ }^{14}$. A busca pela verdade, sob essa ótica, é premissa necessária a ser considerada para que a própria aplicação do direito respeite o ideal de retidão.

Os ecos do relevante debate em questão podem ser ouvidos na realidade pátria. Seguindo a trilha de Luiz Rodrigues Wambier e Eduardo Talamini, tem-se que "todo o processo jurisdicional, na medida em que busca atuar a vontade concreta do ordenamento, visa idealmente à verdade. Trabalha, por conta das limitações humanas, com a verossimilhança, mas sempre buscando a verdade. Agora, existem também outros fatores e valores a considerar: - a impossibilidade de a controvérsia permanecer permanentemente não resolvida - quando não se consegue apurar os fatos; - existência de situações urgentes que exigem proteção provisória em vista da sua aparência; - as peculiaridades concretas da situação de direito material que, por vezes, são incompatíveis com uma reconstrução probatória mais intensa; - a necessidade de a produção das provas respeitar valores jurídicos fundamentais (contraditório, intimidade, integridade física...). Por essas razões é que o direito processual precisa também contemplar mecanismos destinados a dar uma solução ao conflito mesmo quando não se possa atingir a verdade. Mas mesmo esses mecanismos, têm de ser concebidos à luz da ideia de que ao processo interessa, sim, a verdade como importante passo para a realização da justiça. É nesse contexto que têm de ser compreendidos todos os institutos do direito probatório" ${ }^{\prime 15}$.

\subsection{Prova e livre convencimento motivado}

\footnotetext{
${ }^{13}$ CAVALLONE, Bruno. In difesa della veriphobia: considerazioni amichevolmente polemiche su un libro recente di Michele Taruffo. Rivista Di Diritto Processuale, vol. LXV (2010): 1-26, especialmente p. 11-12.

${ }^{14}$ Nas palavras de Michele Taruffo, "Ho solo scritto che poichè nel processo le norme si applicano ai fatti (e ciò non sinifica - mi pare ovvio - confondere i due aspetti del giudizio) l'applicazione dela norma non può ritenersi correta se i fatti non sono stati accertati in modo veritiero" (TARUFFO, Michele. Contro la veriphobia. Osservazione sparsa in risposta a Bruno Cavallone. Rivista Di Diritto Processuale, v. LXV (2010): 999-1011, especialmente p. 1006).

${ }^{15}$ WAMBIER, Luiz Rodrigues, TALAMINI, Eduardo. Curso Avançado de Processo Civil, V. 2. 16 ${ }^{\mathrm{a}}$ ed, São Paulo: Revista dos Tribunais, 2016. p. 226-227.
} 
Revista Eletrônica de Direito Processual - REDP.

Rio de Janeiro. Ano 11. Volume 18. Número 1. Janeiro a Abril de 2017

Periódico Quadrimestral da Pós-Graduação Stricto Sensu em Direito Processual da UERJ

Patrono: José Carlos Barbosa Moreira. ISSN 1982-7636. pp. 302-324

www.redp.uerj.br

Uma versão distinta a respeito da problemática antes apresentada pode ser vista

nas palavras de Araken de Assis, para quem a prova, mesmo não se prestando ao conhecimento da verdade, toma esta última como um "escopo ideal da atividade tendente à demonstração das alegações das partes". Partindo dessa premissa, acaba o autor mencionado por concluir no sentido de que "a função da prova consiste em formar o convencimento do juiz quanto à exatidão das alegações de fato"16.

O livre convencimento motivado é o sistema adotado no art. 371 do CPC, segundo o qual o juiz apreciará a prova constante dos autos, independentemente do sujeito que a tiver promovido, e indicará na decisão as razões da formação de seu convencimento. Salvo exceções específicas (tribunal do júri onde impera a livre convicção do jurado, por exemplo), o magistrado sempre deve demonstrar motivadamente o porquê de sua convicção, o que confere um viés democrático à decisão. Trata-se, aqui, de uma relevante previsão, considerando a necessidade de preservar o caráter democrático da decisão como forma de impedir o exercício arbitrário do poder do Estado.

A livre apreciação da prova segundo critérios de persuasão racional do juiz (outra designação do livre convencimento motivado) parte necessariamente de um pressuposto, qual seja o de que toda e qualquer decisão deve ser pautada por uma racionalidade que permita identificar a sua vinculação às evidências apresentadas no processo ${ }^{17}$. Trata-se de consagrar um modelo no qual se faça possível identificar, em sede de raciocínio probatório, os nexos de causalidade lógico-jurídicos que costuram o discurso judicial a esse respeito ${ }^{18}$. Sob essa ótica, motivar a sentença, além de requisito de validade do comando judicial, é uma forma de controlar a efetividade no que se refere ao direito fundamental à prova ${ }^{19}$.

\footnotetext{
${ }^{16}$ ASSIS, Araken de. Processo Civil Brasileiro. V. II, tomo II. São Paulo: Revista dos Tribunais, 2015. p. 66. ${ }^{17}$ REICHELT, Luis Alberto. A Prova no Direito Processual Civil. Porto Alegre: Livraria do Advogado, 2009. p. 188 .

${ }^{18}$ Interessante transcrever, aqui, a lição de Michele Taruffo: "Senza insistire ulteriormente sulla struttura del giudizio come procedimento di formazione della decisione, ocorre ora vedere in che consista il risultato di tale procedimento, approfondendo la distinzione tra giudizio come attivitta e giudizio come prodotto finale di essa. In quanto il momento conclusivo di tale attività consiste nella scelta di un modelo globale di decisone, la struttura del giudizio come prodotto dell'attività decisoria coincide con quella di siffatto modelo (che cessa di esses una mera ipotesi di decisione per costituire la decisione stabilita in modo definitivo) In questo senso, il giudizio è costituito da un contesto de enunciati (ognuno dei quali è il risultato dele scelte o delle sequenze di scelte esaminate in precedenza), tra loro collegati da nessi di carattere logico-giuridico". (TARUFFO, Michele. La Motivazione Della Sentenza Civile. Cedam: Padova, 1975. p. 256).

${ }^{19}$ Fredie Didier Jr., Paula Sarno Braga e Rafael Alexandria de Oliveira anotam que "Semelhante parece ser a trilha percorrida por Fredie Didier Jr., "a valoração da prova pelo juiz não é livre: há uma série de limitações,
} 
Revista Eletrônica de Direito Processual - REDP.

Rio de Janeiro. Ano 11. Volume 18. Número 1. Janeiro a Abril de 2017

Periódico Quadrimestral da Pós-Graduação Stricto Sensu em Direito Processual da UERJ

Patrono: José Carlos Barbosa Moreira. ISSN 1982-7636. pp. 302-324

www.redp.uerj.br

A supressão da expressão "livremente", que constava do art. 131 do CPC de

1973, dá ensejo a um interessante debate. A redação do novel art. 371 do CPC, segundo Lênio Streck ${ }^{20}$, Lúcio Delfino e Ziel Ferreira Lopes ${ }^{21}$, encamparia a ideia de que o legislador expurgou qualquer resquício do livre convencimento (motivado ou não) do sistema jurídico pátrio. Em sentido contrário, Fernando Gajardoni defende que "a afirmação de que não há mais no Brasil o sistema do livre convencimento parte de um manifesto erro de premissa. A boa previsão legal de standards mínimos de motivação no Novo CPC (art. 489, $\$ 1^{o}$, do CPC?2015) não afeta a liberdade que o juiz tem para valorar a prova. Autonomia na valoração da prova e necessidade de adequada motivação são elementos distintos $e$ presentes tanto no CPC/1973 quando no CPC/2015. A regra do art. 489, $\$ 1^{\circ}$, CPC/2015,

conforme examinado. Além disso, o adjetivo 'livre' era mal compreendido, como se o juiz pudesse valorar a prova como bem entendesse". Ao analisar a circunstância da supressão, no texto do novo CPC, de referências à liberdade na formação do convencimento do juiz, aponta o referido autor que o silêncio do legislador é eloquente, já que "o convencimento do julgador deve ser racionalmente motivado". (DIDIER JR, Fredie, BRAGA, Paulo Sarno, Oliveira, Rafael Alexandria de. Curso de Direito Processual Civil. V. II, $10^{a}$ ed, Salvador: Juspodivm, 2015. p. 102-103). Vale também referir a lição de Guilherme Rizzo Amaral sobre a questão: "O art. 371 trata do princípio da persuasão racional do juiz, segundo o qual é livre a sua convicção quando 'aprecia livremente as provas, sem qualquer limitação legal, e lhes dá o valor que entender adequado', mas, em contrapartida, deve indicar em sua decisão especificamente os motivos que levaram ao seu convencimento" (AMARAL, Guilherme Rizzo. Comentários às Alterações do Novo CPC. São Paulo: Revista dos Tribunais, 2015. p. 494).

${ }^{20}$ Sobre o destacado, as palavras de Lênio Streck são as seguintes: "O NCPC ao retirar o poder de livre convencimento ou livre apreciação, assume um nítido sentido "não protagonista", agastado o velho instrumentalismo e os fantasmas do antigo "socialismo processual" (büllow, Menger, Klein). Não se pode mais invocar, igualmente o princípio (sic) da presunção racional. O novo Código não compactua com presunções, mesmo que venham com epítetos como "racional", etc. Trata de uma opção paradigmática feita pelo legislador. A decisão judicial exige exercício prático, senso de dever, capacidade de se adotar uma atitude reflexiva em relação às próprias pré-compreensões, garantia de coparticipação dos destinatários da decisão no processo deliberativo, aprendizado institucional e debate público. Isto não quer dizer que o juiz se transformou em um exegeta do século XIX ou que esteja proibido de interpretar. O CPC apenas passou a lhe exigir responsabilidade política e suspensão de seus prejuízos sobre o mundo e os fatos a interpretar-julgar. Todos temos précompreensões. Mas isso não significa que somos reféns delas. E, como fica claro em Verdade e Consenso, précompreensão (Vorverständnis) não é igual a preconceitos no sentido vulgar. O que o legislador do novo CPC quer é que as decisões judiciais sejam ditadas segundo o direito e não conforme o pensar individual dos julgadores" (STRECK, Lênio Luiz. As Provas e o Novo CPC: a extinção do Poder de Livre Convencimento.IN: FELIX JOBIM, Marco, SANTOS FERREIRA, William (org.) Direito Probatório. $2^{\mathrm{a}}$ ed.,. Salvador: Juspodivm, 2015. p. 111).

${ }^{21}$ Nas palavras dos citados autores, " se é para levar o novo CPC a sério, não se pode contentar com um mero "livre-convencimento-mais-motivado". Tragamos Gadamer para o processo civil: o livre convencimento não deve ser combatido; deve ser destruído. A verdade é que o "princípio" do livre convencimento motivado não se sustenta em um sistema normativo como o novo CPC, que aposta suas fichas no contraditório como garantia de influência e não surpresa e, por isso, alimenta esforços para se ajustar ao paradigma da intersubjetividade, em que o processo é encarado como um locus normativamente condutor de trabalho na qual todos os sujeitos processuais atuam em viés interdependente e auxiliar, com responsabilidade na construção e efetivação dos provimentos judiciais" (DELFINO, Lúcio, LOPES, Ziel Ferreira. A expulsão do Livre Convencimento Motivado do Novo CPC: porque a razão está com os hermeneutas? In: MACÊDO, Lucas Buril de, PEIXOTO, Ravi e FREIRE, Alexandre (Org.). Processo de Conhecimento - Provas. Salvador: Juspodivm, 2015. p. 310). 
Revista Eletrônica de Direito Processual - REDP.

Rio de Janeiro. Ano 11. Volume 18. Número 1. Janeiro a Abril de 2017

Periódico Quadrimestral da Pós-Graduação Stricto Sensu em Direito Processual da UERJ

Patrono: José Carlos Barbosa Moreira. ISSN 1982-7636. pp. 302-324

www.redp.uerj.br

trata do $2^{\circ}$ elemento (motivação), e não do $1^{o}$ (liberdade na valoração da prova). Ademais, os artigos 371 e 372 comprovam a afirmação que subsiste a liberdade de valoração da prova no CPC/2015, ao indicar que o juiz apreciará a prova atribuindo-lhe o valor que entender adequado (isso não é livremente?) devendo, contudo, indicar as razões da formação de seu convencimento" ${ }^{22}$.

No contexto do livre convencimento motivado, tem-se que não raro ocorrerá o surgimento de restrições substanciais à possibilidade de conhecimento pleno da realidade histórica. Ao mesmo tempo em que a investigação dos fatos é tendente ao conhecimento da realidade histórica, é igualmente verdadeiro que o novo Código de Processo Civil assumiu uma série de outros compromissos, os quais, em especiais circunstâncias (especiais sim, raras não), podem ser aparentemente colidentes com o atingimento desse objetivo. $\mathrm{O}$ aprofundamento da investigação probatória tende a retardar o andamento do feito. Na equação entre busca pela verdade e celeridade na tramitação do processo, impõe-se sempre maximizar a efetiva aplicação conjunta dos primados referidos, de modo que as restrições impostas a cada um deles seja a menor possível. Trata-se de uma leitura que densifica o compromisso com o postulado da proporcionalidade ${ }^{23}$, justificando, por exemplo, que o magistrado, diante de evidências suficientes, possa em certos casos encerrar a atividade de instrução e imediatamente proferir decisão na forma do art. 355 do CPC.

\section{Questões sobre a efetividade do direito fundamental à prova no novo CPC.}

Adentrando-se, agora, em questões mais específicas no que tange a efetividade do direito à prova, duas questões em particular merecem análise mais detida. A primeira diz respeito ao impacto exercido pela introdução efetiva do cross-examination no sistema da prova oral. A segunda, por sua vez, é a relativa à produção da prova pericial sob a ótica dos negócios processuais, iluminando-se, em especial, a possibilidade de eleição do perito pelas partes, bem como o estabelecimento de calendário processual.

\subsection{O cross-examination e a produção da prova oral}

\footnotetext{
22 GAJARDONI, Fernando da Fonseca. O Livre Convencimento Motivado Não Acabou no Novo CPC. Em: <http://jota.info/o-livre-convencimento-motivado-nao-acabou-no-novo-cpc>, Acesso em: 28 de Setembro de 2016.

${ }_{23}$ ÁVILA, Humberto. Teoria dos Princípios - da Definição à Aplicação dos Princípios Jurídicos. $13^{\mathrm{a}}$ ed. São Paulo: Malheiros, 2012. p. 183.
} 
Revista Eletrônica de Direito Processual - REDP.

Rio de Janeiro. Ano 11. Volume 18. Número 1. Janeiro a Abril de 2017

Periódico Quadrimestral da Pós-Graduação Stricto Sensu em Direito Processual da UERJ

Patrono: José Carlos Barbosa Moreira. ISSN 1982-7636. pp. 302-324

www.redp.uerj.br

A aproximação entre os sistemas de common law e de civil law é um fenômeno

que ganha cada vez maior aprofundamento ${ }^{24}$. No contexto do novo CPC brasileiro, uma das mais emblemáticas manifestações pode ser vista na sistemática adotada em sede de oitiva de testemunhas.

Na ótica do CPC de 1973, o interrogatório das testemunhas desenvolvia-se mediante um modelo de condução presidencialista da audiência. Sob o signo desse modelo, a parte, através do seu advogado, acabava por direcionar ao juiz a pergunta a ser respondida pela testemunha, cabendo ao magistrado, por sua vez, determinar se a testemunha deveria ou não responder ao indagado.

No modelo do novo CPC, observa-se uma substancial mudança, com direta influência do paradigma vigente no common $\operatorname{law}^{25}$. De acordo com o art. 459 da novel codificação, as perguntas serão formuladas pelas partes, através dos seus advogados, diretamente à testemunha. Deixa-se, assim, a sistemática presidencialista da audiência para um sistema no qual se permite a elaboração de questionamentos diretos (direct examination).

Nesse contexto, especial papel exerce a figura do cross-examination, que consiste na possibilidade de o advogado interrogar diretamente a testemunha arrolada pela

\footnotetext{
${ }^{24}$ DAVID, Rene e JAUFFRET-SPINOSI, Camille. Los grandes sistemas jurídicos contemporáneos. México: Instituto de Investigaciones Jurídicas, 2010. p. 13 e seguintes.

${ }^{25}$ A utilização do cross-examination é prática comum nos países de Common Law. Conforme Paula Loughlin e Stephen Gerlis "as a general rule, any evidence that needs to be proved by a witness at trial must be proved by their oral evidence given in public, but in any other hearing is to be proved by their evidence in writing ( $\mathrm{r}$ 32.2(1)). This general rule usually applies so that at most trials witness evidence is given orally, whilst at interim hearings it is usually given by means of witness statements, or even a statement of case or application notice verified by a statement of truth (see also $r$ 32.6). The general rule will not apply if there is any provision to the contrary in the rules ( $\mathrm{r} 32.2(2)$ ). So, for instance, for Part 8 claims, where there is no substantial dispute of fact, the court is unlikely to order the attendance of witnesses at the trial and will instead rely on their written evidence (r 8.6). The court has no power to order that a party must call a witness it has identified but decided not to call so that the witness is available for cross-examination by the other party. The court has no discretion to require a party to call evidence which it was not minded to call (The Society of Lloyd's v Jaffray (2000) The Times, 3 August)". E segue a lição dos autores: "As a general rule, if a party has served a witness statement and he wishes to rely at trial on the evidence of the witness who made the statement, he must call that witness to give oral evidence (r 32.5(1)). However, a party is not obliged to call that witness to give evidence and may instead adduce the statement as hearsay evidence (Douglas and Zeta-Jones v Hello! Ltd [2003] EWCA Civ 332; and see below, 'Adducing witness statement as hearsay evidence'). The usual rule, unless the court orders otherwise, is that where a witness is called to give oral evidence his witness statement stands as his evidencein-chief ( $\mathrm{r} 32.5(2)$ ). This rule is now almost universally applied, being considered to reduce the length and cost of the trial. Where a witness is called to give evidence at trial he may be cross-examined on his witness statement, whether or not the statement or any part of it was referred to during the witness's evidence-in-chief (r 32.11)." (LOUGHLIN, Paula e GERLIS, Stephen. Civil Procedure. $2^{\mathrm{a}}$ ed. Londres: Cavendish Publishing, 2004. p. 475).
} 
Revista Eletrônica de Direito Processual - REDP.

Rio de Janeiro. Ano 11. Volume 18. Número 1. Janeiro a Abril de 2017

Periódico Quadrimestral da Pós-Graduação Stricto Sensu em Direito Processual da UERJ

Patrono: José Carlos Barbosa Moreira. ISSN 1982-7636. pp. 302-324

www.redp.uerj.br

parte contrária ${ }^{26}$. A fim de que se possa compreender a dimensão do fenômeno mencionado, lembre-se a lição de Michele Taruffo ao anotar que "o interrogatório cruzado ou contrainterrogatório é o 'o melhor instrumento jurídico jamais inventado para a descoberta da verdade". Ainda segundo o referido autor, o cross-examination teria ao menos dois objetivos: "o primeiro é obter da testemunha algumas respostas que podem ser favoráveis à parte que o realiza; o segundo, e provavelmente mais importante, é provocar o impedimento da testemunha adversa demonstrando que não é confiável e que carece de credibilidade, por ter um interesse pessoal na causa ou qualquer outra razão, levantar dúvidas acerca da sua personalidade, bem como desacreditar seu testemunho por qualquer outro motivo"27

Há, aqui, uma mudança muito mais relevante do que inicialmente se possa perceber em um cenário no qual a doutrina festeja o novo como suposto avanço ${ }^{28}$. Retira-se do magistrado a função de filtrar as perguntas a serem respondidas quando da oitiva da testemunha, estabelecendo-se um modelo de condução da audiência de instrução permeado por uma visão liberal, a pretexto de assegurar maior simplificação da forma dos atos processuais, com pretenso ganho de agilidade no desenvolvimento do debate.

A ânsia de buscar um processo célere pode, contudo, ensejar a tomada de atitudes que levam ao surgimento de alguns efeitos colaterais. Nesse sentido, a forma como se

\footnotetext{
${ }^{26}$ Como destaca José Miguel Garcia Medina, “o art. 459 do CPC/2015 permite que as partes façam as perguntas diretamente às testemunhas, independentemente de imediação do juiz (diversamente, pois, do que previa o art. 416 do CPC/1973). Nesse sentido é também o artigo 212 do CPP, segundo o qual 'as perguntas serão formuladas elas partes diretamente à testemunha'. Ambas as partes podem fazer perguntas à testemunha (isso é, a parte que a arrolou e, também, a parte adversária). Algo semelhante é admitido pela legislação processual civil norte-americana, que admite que as partes façam perguntas, seja às testemunhas que indicaram (directexamination), seja àquelas indicadas pela parte adversária (cross-examination)” (MEDINA. José Miguel Garcia. Novo Código de Processo Civil Comentado. São Paulo: Revista dos Tribunais, 2015. p. 699)

27 TARUFFO, Michele. A Prova. São Paulo: Marcial Pons, 2014. p. 121-122.

28 Vale destacar o quanto refere Guilherme Rizzo Amaral: "O atual CPC atendeu ao anseio doutrinário, estabelecendo que 'as perguntas serão formuladas pelas partes diretamente à testemunha, começando pela que à arrolou' A referência a partes deve, logicamente, ser interpretada como advogados das partes. À parte stricto sensu não é dado fazer perguntas, salvo quando se tratar de advogado em causa própria ou nos raros casos em que detiver jus postulandi." (AMARAL, Guilherme Rizzo. Comentários às Alterações do Novo CPC. São Paulo: Revista dos Tribunais, 2015. p. 563). Também vale referência à Thiago Fernandes Chebatt e Giovani dos Santos Ravagnani: "Além disso, foram incorporadas à prova testemunhal práticas da common law, principalmente do sistema norte americano, tendo sido retirada a exclusividade estatal para intimação das testemunhas, que passa a poder ser feita diretamente pelos advogados, que somente recorrerão ao judiciário em casos extremos. Ainda nesse contexto, passa a ser possível agora a inquirição direta da testemunha pelo advogado, extinguindo o obsoleto e ineficiente sistema de reperguntas hoje vigente, tudo para que o procedimento seja mais rápido e eficaz". (CHEBATT, Thiago Fernandes, RAVAGNANI, Giovani dos Santos. Considerações Sobre a Prova Testemunhal no Novo Código de Processo Civil. In: MACÊDO, Lucas Buril de, PEIXOTO, Ravi e FREIRE, Alexandre (Org.). Processo de Conhecimento - Provas. Salvador : Juspodivm, 2015. p. 593).
} 
Revista Eletrônica de Direito Processual - REDP.

Rio de Janeiro. Ano 11. Volume 18. Número 1. Janeiro a Abril de 2017

Periódico Quadrimestral da Pós-Graduação Stricto Sensu em Direito Processual da UERJ

Patrono: José Carlos Barbosa Moreira. ISSN 1982-7636. pp. 302-324

www.redp.uerj.br

estrutura o cross-examination, mediante a formulação de perguntas diretas, pode gerar substancial prejuízo no que se refere à qualidade do resultado da atividade de instrução.

Se, de um lado, a ideia do cross-examination não é completamente nova em nosso ordenamento, já que anteriormente consagrada no art. 212 do Código de Processo Penal, isso também não serve como justificativa para que se sustente a preferência pela novel orientação adotada pelo novo CPC. As diferenças substanciais entre o Direito Processual Penal e o Direito Processual Civil, notadamente no que se refere à preocupação em relação ao papel exercido pela presunção de inocência no primeiro, necessariamente fazem com que haja razões presentes na dinâmica da investigação criminal que não necessariamente se replicam no âmbito cível.

Não está a se dizer que a nova sistemática está fadada ao fracasso ou que necessariamente irá causar tumultos nos processos, até porque, em alguma medida, antes mesmo do advento do novo CPC já era possível encontrar magistrados que renunciavam a ideia da repergunta e permitiam que os questionamentos fossem feitos diretamente às testemunhas. O fato é que a novel sistemática reclama atenção para uma série de riscos iminentes.

Um primeiro risco a ser ponderado é o do surgimento de prejuízos nos casos em que figurem como testemunhas pessoas desacostumadas com o ambiente judicial, que podem facilmente se sentir melindradas ou acanhadas. Se a posição de testemunha é, não raro, compreensivelmente desconfortável, inserida em ambiente estranho ao de seu convívio natural. Estando diante de um juiz e sendo questionada diretamente por um advogado habilidoso, uma testemunha frágil pode ser facilmente desestabilizada, gerando um relato que pouco ou nada serve para descrever a realidade. O filtro judicial, nesse sentido, servia como uma ferramenta a garantir direitos e prerrogativas de todos os sujeitos que comparecem ao debate.

Assim, cresce em importância a figura do juiz como responsável pelo controle para que a produção da prova testemunhal não escape ao principal objetivo da atividade de instrução ${ }^{29}$. O magistrado terá que necessariamente agir de forma a coibir qualquer forma de

\footnotetext{
${ }^{29}$ A esse respeito, anota Marcelo Abelha Rodrigues que "a malícia, a expertise, o domínio das palavras, a experiência forense, e o conhecimento das fragilidades humanas são aspectos que associados à forma como alguém formula uma indagação, permitem que se extraia uma resposta menos comprometida com a verdade dos fatos, porém muito mais próxima do interesse de quem formula a indagação" (in WAMBIER, Teresa
} 
Revista Eletrônica de Direito Processual - REDP.

Rio de Janeiro. Ano 11. Volume 18. Número 1. Janeiro a Abril de 2017

Periódico Quadrimestral da Pós-Graduação Stricto Sensu em Direito Processual da UERJ

Patrono: José Carlos Barbosa Moreira. ISSN 1982-7636. pp. 302-324

www.redp.uerj.br

manipulação da testemunha por parte do procurador de uma das partes. O próprio caput do art. 459 do CPC refere ser vedada a indução da testemunha, mas existem diversas maneiras de causar transtorno em um depoimento. O papel fiscalizador do juiz será fundamental para que a audiência transcorra de forma suave, evitando abusos e importunações à pessoa da testemunha, para que essa possa, de forma clara e tranquila, destacar o que percebeu do fato controvertido.

O que efetivamente causa incômodo no sistema do cross-examination como formatado pelo legislador brasileiro é que sua justificativa parece insuficiente. Veja-se que o sistema de reperguntas não atrasa o processo de forma significativa. Não se imagina que o tempo gasto entre o tempo de o juiz levar a pergunta ao depoente efetivamente cause um atraso no andamento do feito a ponto de causar uma morosidade processual. Também o argumento de que o juiz ao levar a pergunta para a testemunha pode mudar o sentido da mesma igualmente não convence, pois é lícito ao advogado retificar o questionamento ${ }^{30}$. De outro lado, o sistema presidencialista da audiência confere uma natural proteção à testemunha por parte do juiz, em que este exerce um filtro na agressividade ou na malícia das perguntas, fazendo valer de maneira mais efetiva o constante do art. $459, \S 2^{\circ}$ do CPC.

\subsection{A prova pericial sob a perspectiva dos negócios processuais - a eleição do perito e o calendário processual.}

A possibilidade de autorregulação da vontade das partes, traço usualmente associado ao âmbito do Direito Privado, ganhou nova roupagem em função do advento do novo $\mathrm{CPC}^{31}$. O art. 190 do CPC quebra o paradigma da legislação anterior ao permitir que

\footnotetext{
Arruda Alvim, DIDIER JR, Fredie, TALAMINI, Eduardo e DANTAS, Bruno (org.). Breves Comentários ao Novo Código de Processo Civil. São Paulo: Revista dos Tribunais, 2015. p. 1161).

${ }^{30}$ Em obra anterior ao novo CPC, Luiz Guilherme Marinoni e Sergio Cruz Arenhart assim se manifestaram: "o ideal seria que os advogados e o representante do Ministério Público pudessem formular as suas perguntas diretamente à testemunha, evitando-se o risco de o juiz formular outra pergunta, no sentido de pergunta diversa à testemunha". (MARINONI, Luiz Guilherme, CRUZ ARENHART, Sergio. Comentários ao Código de Processo Civil. São Paulo: Revista dos Tribunais, 2005. p. 559).

${ }^{31}$ Nesse sentido, é válido o quanto destacado por Fredie Didier Jr: "O Direito Processual Civil, embora ramo do Direito Público, ou talvez exatamente por isso, também é regido por essa dimensão da liberdade. O princípio da liberdade também atua no processo, produzindo um subprincípio: o princípio do respeito ao autorregramento da vontade no processo. É certo que esse princípio não tem, no Direito Processual Civil, a mesma roupagem dogmática com que se apresenta, por exemplo, no Direito Civil. Por envolver o exercício de uma função pública (a jurisdição), a negociação processual é mais regulada e seu objeto, mais restrito. Isso, porém, não diminui a sua importância, muito menos impede que se lhe atribua o merecido destaque de ser um dos princípios estruturantes no Direito Processual Civil brasileiro, uma de suas normas fundamentais" (DIDIER JR, Fredie.
} 
Revista Eletrônica de Direito Processual - REDP.

Rio de Janeiro. Ano 11. Volume 18. Número 1. Janeiro a Abril de 2017

Periódico Quadrimestral da Pós-Graduação Stricto Sensu em Direito Processual da UERJ

Patrono: José Carlos Barbosa Moreira. ISSN 1982-7636. pp. 302-324

www.redp.uerj.br

as partes possam, naqueles processos que admitam autocomposição, estabelecer parâmetros procedimentais específicos a serem observados em determinado processo. Aliás, a ampla possibilidade de estabelecimento de negócios jurídicos processuais guarda sintonia com a ideia de um processo colaborativo ${ }^{32}$, em um contexto no qual a maior margem de liberdade reconhecida pelo legislador permite que as partes possam celebrar convenções processuais atípicas, diferentemente do previsto na sistemática anterior, na qual tais pactos somente seriam possíveis nos casos taxativamente elencados em lei.

A realização de negócios jurídicos processuais em matéria probatória pode gerar certa polêmica. Um questionamento importante é o que envolve saber se seria permitido às partes estipular no sentido de que determinada prova não pudesse ser produzida no debate processual $^{33}$. Tratar-se-ia, aqui, de estipular limites não só às condutas dos contratantes, mas também em relação à atuação judicial.

Impõe-se, nesse ponto, traçar a linha de um limite a ser considerado pelas partes, uma vez que o processo não pertence exclusivamente a elas. É de interesse do próprio Estado que a decisão judicial seja construída com base no cenário mais aproximado possível em relação àquilo que se passou do ponto de vista histórico, e, para tanto, deve-se permitir a

\footnotetext{
Princípio do Respeito ao Autorregramento da Vontade no Processo Civil In: CABRAL, Antonio do Passo e NOGUEIRA, Pedro Henrique (Org.). Negócios Processuais. Salvador: Juspodivm , 2015. p. 32-33).

${ }^{32}$ Como diz Leonardo Carneiro da Cunha: "Como efeito, o novo CPC contém diversas normas que prestigiam a autonomia da vontade das partes, permitindo que elas negociem sobre o processo de modo mais evidente que no CPC/1973. O autorregramento da vontade no processo é permitido, assegurado e respeitado. O novo Código é estruturado de maneira a estimular a solução do conflito pela via que parecer mais adequada a cada caso, não erigindo a jurisdição como necessariamente a melhor opção para eliminar a disputa de interesses. $\mathrm{O}$ novo Código trata, por exemplo, da autocomposição regulando a mediação e a conciliação (art. 165 a 175), inserindo a tentativa de autocomposição como ato anterior à defesa do réu (arts. 334 a 695), permitindo, no acordo judicial, a inclusão de matéria estranha ao objeto litigioso do processo (art., $515, \S 2^{\circ}$ ) e admitindo acordos sobre o processo (art. 190). Há, enfim, um estímulo a autocomposição, destacando-se os $\S \S 2^{\circ}$ e $3^{\circ}$ do seu art. $3^{\circ}$. A consagração do princípio da cooperação (art. $6^{\circ}$ ) relaciona-se com o fenômeno da valorização da autonomia da vontade no processo. O art. 190 prevê uma cláusula geral de negociação processual, permitindo a celebração de negócios processuais atípicos" (CUNHA, Leonardo Carneiro da. Negócios Jurídicos Processuais no Processo Civil Brasileiro. Civil. In: CABRAL, Antonio do Passo e NOGUEIRA, Pedro Henrique (Org.). Negócios Processuais. Salvador: Juspodivm , 2015. p. 62). Sobre o paradigma colaborativo, ver, ainda, MITIDIERO, Daniel. Colaboração no Processo Civil. São Paulo: Revista dos Tribunais, 2009.

${ }^{33}$ Nesse sentido é o que sustenta Robson Renault Godinho: "A formação de negócios processuais probatórios necessariamente afetará os poderes instrutórios do juiz e esse ponto seguramente será fonte de intensas controvérsias, simetricamente ao que ocorre precisamente sobre a própria extensão de tais poderes. Para quem entende que os poderes instrutórios do juiz apenas devem assumir um papel subsidiário e complementar às atividades das partes, necessariamente seu balizamento em virtude de negócios probatórios será natural e automático. Entender de modo diverso significará concluir que o consenso pode ser superado, o que reduzirá significativamente seu âmbito de incidência, deixando-o a critério de um ato de vontade estatal" (GODINHO, Robson Renault. A Possibilidade de Negócios Jurídicos Processuais Atípicos em Matéria Probatória. In: CABRAL, Antonio do Passo e NOGUEIRA, Pedro Henrique (Org.). Negócios Processuais. Salvador: Juspodivm , 2015. p. 533).
} 
Revista Eletrônica de Direito Processual - REDP.

Rio de Janeiro. Ano 11. Volume 18. Número 1. Janeiro a Abril de 2017

Periódico Quadrimestral da Pós-Graduação Stricto Sensu em Direito Processual da UERJ

Patrono: José Carlos Barbosa Moreira. ISSN 1982-7636. pp. 302-324

www.redp.uerj.br

utilização de tantos meios de prova quantos forem necessários, seja pelas partes, seja pelo

julgador. Nesse sentido, não podem as partes firmar que a prova pericial está dispensada quando o juiz, através de seus poderes instrutórios, pode entender pela necessidade de produção de tal prova ${ }^{34}$.

Reforce-se, ainda, que a parte não produzir determinada prova por simples opção é diferente de impedir que esta prova venha a ser produzida pelo magistrado. Nesse último caso, estar-se-ia pactuando fora do âmbito de disponibilidade das partes, o que lhes é defeso.

Com isso, não se está a afirmar que negócios processuais não podem ser realizados no que tange às provas. Ao contrário: um exemplo expresso a ilustrar a margem de liberdade de contratação está no art. 471 do CPC, segundo o qual as partes podem, de comum acordo, escolher o perito. Perceba-se que não está ocorrendo uma limitação à produção de provas, mas antes, o que se vê é a possibilidade de investigação dentro do espírito colaborativo e de busca de consenso transversal ao CPC.

A chamada perícia consensual se dará quando as partes apresentarem ao juiz o perito de sua preferência, para que realize a prova técnica. Nesta hipótese, o perito consensual substituirá o perito do juízo. Segundo Guilherme Rizzo Amaral, “o art. 471 inova ao instituir a chamada perícia consensual, que se dará quando as partes, de comum acordo, indicarem ao juiz perito de sua preferência. Neste caso, desde que capazes as partes e se trate de litígio sobre direitos disponíveis - do contrário, inadmissível será o meio consensual - o juiz deverá homologar a escolha das partes, hipótese em que a perícia consensual substituirá para todos os efeitos, a perícia que seria realizada pelo perito nomeado pelo juiz" ${ }^{\prime 35}$.

\footnotetext{
${ }^{34}$ Em posição contrária ao quanto defendido está a posição de Fredie Didier Jr, Paula Sarno Braga e Rafael Alexandrino: "A parte pode expressamente dispor de seu direito de produzir determinada prova, seja unilateralmente, seja mediante acordo firmado com a parte adversária (pode ser que as partes resolvam firmar acordo de, por exemplo, não realização de perícia; elas podem imaginar que não vale a pena aguardar pela produção dessa modalidade de prova para que o litígio alcance um desfecho). Pode ser, ainda, que uma das partes, sozinha, resolva expressamente abrir mão da perícia, ou de qualquer outro meio de prova. Não há inércia, mas vontade manifestada: não se quer a produção de determinado meio de prova. Nesses casos, poderia o juiz, com base no art. 370 do CPC, determinar, ainda assim a produção da prova? Parece-nos que não. Temse aí típico exemplo de negócio jurídico processual - unilateral quando a manifestação de vontade vem de apenas uma das partes; bilateral, quando de ambos os polos. Se válido, o juiz não pode ignorar esse ato de vontade. Se o fizesse, isso seria o mesmo que negar às partes o protagonismo da cena processual, assumindoo somente para si" (DIDIER JR, Fredie, BRAGA, Paulo Sarno, Oliveira, Rafael Alexandria de. Curso de Direito Processual Civil. V. II. 10 a ed, Salvador: Juspodivm, 2015. p. 90-91).

${ }^{35}$ AMARAL, Guilherme Rizzo. Comentários às Alterações do Novo CPC. São Paulo: Revista dos Tribunais, 2015. p. 572.
} 
Revista Eletrônica de Direito Processual - REDP.

Rio de Janeiro. Ano 11. Volume 18. Número 1. Janeiro a Abril de 2017

Periódico Quadrimestral da Pós-Graduação Stricto Sensu em Direito Processual da UERJ

Patrono: José Carlos Barbosa Moreira. ISSN 1982-7636. pp. 302-324

www.redp.uerj.br

Possibilitar as partes que façam a escolha em conjunto do perito vai ao encontro do espírito de colaboração presente no CPC. Há, contudo, um fator interessante a ser ponderado: também aqui é possível vislumbrar um viés ideológico liberal peculiar, visto que a legislação dispôs no sentido de que as partes acabam por escolher um especialista que será o de preferência das partes. A confiança do magistrado no perito ocupa posição menos importante em detrimento de exigências que se apresentam como primordiais nesse contexto, em especial a de imparcialidade do expert.

Da escolha do perito pelas partes decorrem consequências práticas importantes. Uma vez tendo as partes eleito o perito conjuntamente, é corolário natural a diminuição da chance de impugnação ao laudo apresentado. Ainda que persista a possibilidade de indicação de um assistente técnico, mesmo no caso de consenso quanto ao perito, dificilmente surgirão questionamentos sérios sobre o parecer do expert, uma vez que de confiança das partes. A restrição ao duplo grau de jurisdição, nesse contexto, é compensada mediante o potencial incremento em termos de celeridade do processo, que é associado à efetividade desejada no que tange ao direto fundamental à prova.

No entanto, a escolha do perito, ainda que consensual, deve ser alvo de controle do juiz, em especial no que tange a capacidade e aptidão do mesmo com vistas à análise do tema controvertido alvo da prova técnica. Se o magistrado compreender que o perito não possui a expertise necessária para realizar a prova, poderá ele afastar o profissional, sendo declarada nula a cláusula do acordo firmado entre as partes, e designar outro que atenda ao estabelecido no ordenamento jurídico ${ }^{36}$.

A possibilidade de escolha do expert pelas partes traz, ainda, outras reflexões. Da mesma forma que ocorre em se tratando do perito designado pelo juiz, tem-se que o julgador não está adstrito às conclusões apresentadas no laudo pericial do perito indicado pelas partes. Tanto no caso de acolhimento quanto no caso de rejeição das conclusões do laudo pericial, impõe-se ao juiz decidir de maneira fundamentada, podendo, até mesmo,

\footnotetext{
${ }^{36}$ José Miguel Garcia Medina concorda com o quanto destacado ao referir que "Haverá controle do juiz a respeito desse negócio processual - p.ex., recusando o perito que não qualificação técnica, acrescentando quesitos e - no curso da realização da perícia, manifestar-se, sendo o caso, sobre o método empregado e, por fim, valorar a perícia. A escolha do perito pelas partes, de todo modo, deve ser estimulada pelo juiz, pois tem a aptidão de evitar que se discuta, no futuro, sobre a idoneidade do perito e, quiçá, sobre o próprio resultado da perícia (isso é, sobre o teor do laudo pericial)" (MEDINA. José Miguel Garcia. Novo Código de Processo Civil Comentado. São Paulo: Revista dos Tribunais, 2015. p. 711).
} 
Revista Eletrônica de Direito Processual - REDP.

Rio de Janeiro. Ano 11. Volume 18. Número 1. Janeiro a Abril de 2017

Periódico Quadrimestral da Pós-Graduação Stricto Sensu em Direito Processual da UERJ

Patrono: José Carlos Barbosa Moreira. ISSN 1982-7636. pp. 302-324

www.redp.uerj.br

designar nova perícia ${ }^{37}$. A navegação em relação a esse tema, contudo, não se dá em águas

tranquilas, já que há respeitáveis vozes levantando importantes questões a seu respeito ${ }^{38}$. É de se reconhecer, contudo, que a designação de nova perícia após apresentado o laudo pelo expert indicado pelas partes é admissível, tendo em vista que a definição quanto à existência e ao alcance dos poderes instrutórios do juiz não se situa na esfera de disposição das partes.

Outra novidade trazida pelo CPC em matéria de negócios jurídicos processuais em matéria probatória consta do art. $357, \S 8^{\circ}$, o qual, na trilha do disposto no art. 191, prevê a possibilidade de estabelecimento de um calendário processual para fins de produção de prova pericial. Inspirada na experiência italiana ${ }^{39}$, tal prática busca dar maior celeridade ao processo, suprimindo considerável parte da tramitação cartorial burocrática estatal. Outro ganho de qualidade reside no avanço em termos de previsibilidade no que se refere ao estabelecimento da marcha do processo, no que se cria um contraste agudo na comparação

\footnotetext{
${ }^{37}$ Vale referir a ideia de Luiz Guilherme Marinoni e Sérgio Cruz Arenhart: "Se o juiz não está convencido com a perícia realizada - seja porque o seu método ou o seu resultado é duvidoso e não esclarecedor, seja porque o subscritor do laudo se revelou pessoa não confiável - deve ser feita nova perícia, com o mesmo objeto e finalidade da já produzida" (MARINONI, Luiz Guilherme, ARENHART, Sérgio Cruz. Prova e Convicção. $3^{\mathrm{a}}$ ed. São Paulo: Revista dos Tribunais, 2015. p. 880-881).

${ }^{38}$ Vale trazer a posição de Fredie Didier Jr., Paula Sarno Braga e Rafael Alexandria de Oliveira, os quais entendem de forma diversa do quanto defendido no presente trabalho: "É possível a existência de negócios probatórios atípicos. Uma vez observados os pressupostos do art.190 e sendo válido o negócio jurídico processual, o juiz fica a ele vinculado. Alguns exemplos - relembre-se: é preciso que negócio processual seja válido: a) se as partes acordarem no sentido de não ser produzida prova pericial, o juiz não pode determinar a produção desse meio de prova; b) se a parte renunciar a certo testemunho, o juiz não pode determinar a sua produção; c) se houver convenção sobre o ônus da prova (art. 373 , $\S \S 3^{\circ} 34^{\circ}$ ), o juiz não pode decidir contra o que foi convencionado. O poder instrutório do juiz tem essa limitação, enfim" (DIDIER JR, Fredie, BRAGA, Paulo Sarno, Oliveira, Rafael Alexandria de. Curso de Direito Processual Civil. V. II. 10 a ed, Salvador: Juspodivm, 2015. p. 90-91). Ainda que não digam expressamente sobre a possibilidade de produção de uma nova perícia do juízo quando houve a escolha de perito consensual, fica clara a posição dos autores referidos em aceitar como possível a limitação os poderes instrutórios do juiz. Há também a posição de Luiz Rodrigues Wambier e de Eduardo Talamini: "O juiz pode determinar a realização de uma segunda perícia se reputar a primeira insatisfatória para a formação do seu convencimento. Mas frise-se que essa segunda perícia haverá de ser realizada por perito consensual, a não ser que outra seja a deliberação das partes. Admitir-se uma segunda perícia por perito definido pelo juiz implicaria tornar irrelevante a possibilidade de escolha do perito pelas partes - fazendo do art. 471 do CPC/2015 letra morta" (WAMBIER, Luiz Rodrigues, TALAMINI, Eduardo. Curso Avançado de Processo Civil, V. 2. 16 ${ }^{\mathrm{a}}$ ed, São Paulo: Revista dos Tribunais, 2016. p. 346).

${ }^{39}$ É possível visualizar tal afirmativa através do que refere Elisa Picozza: "La 1.18 giugno 2009, n.69, mette nuovamente mano - a distanza di pochi anni - al processo civili., Tra le varie novità volte - se non próprio ad accelerate i tempi di svogliamento del processo quanto meno - a consentire alle parti una previsione della sua durata, figura oggi il calendário del processo, introtto dal nuovo art. 81 bis delle disposizioni attuazione del nostro codice di rito" (PICOZZA, Elisa. Il Calendario del Processo. Rivista di Diritto Processuale, v. 64, $n$. 6, 2009, p. 1652). Com ganho, é possível consultar também PICCININNI, Leo. Le Recenti Riforme Della Giustizia Civile Italiana Tra Esigenze Di Semplificazione, Accelerazione Ed Effettività Della Tutela. In: MARTÍN, Agustín Jesús Pérez-Cruz e BAAMONDE, Xulio Ferreiro (org.). Los retos del Poder Judicial ante la sociedad globalizada. Actas del IV Congreso Gallego de Derecho Procesal (I Internacional) A Coruña, 2 y 3 de junio de 2011. A Coruña: Universidade, 2012, p. 147-164, especialmente p. 151.
} 
Revista Eletrônica de Direito Processual - REDP.

Rio de Janeiro. Ano 11. Volume 18. Número 1. Janeiro a Abril de 2017

Periódico Quadrimestral da Pós-Graduação Stricto Sensu em Direito Processual da UERJ

Patrono: José Carlos Barbosa Moreira. ISSN 1982-7636. pp. 302-324

www.redp.uerj.br

com a atual realidade judicial, em que é virtualmente impossível antever com maior precisão

e antecedência a partir de quando determinado irá ser praticado ou quando determinada atividade terá fim.

A prática de construção consensual do referido calendário, a míngua de maior experiência, parece saudável. Primeiro, permite que as partes tenham uma noção mais apurada da duração do processo, que assume feições razoáveis, nos termos da exigência constante do art. $5^{\circ}$, LXXVIII do texto constitucional. O avanço em termos de organização e uma previsibilidade no processo tende a resultar em maior efetividade da tutela jurisdicional. Há um potencial ganho em termos de agilidade na tramitação do processo, uma vez que, estabelecidas as datas para a prática dos atos, dispensa-se a intimação das partes, escapando-se da morosidade cartorária em expedir e publicar as notas de expediente. Como consequência direta da desnecessidade de intimação, resulta a tendente redução do número de nulidades decorrentes de error in procedendo ${ }^{40}$.

Há, ainda, um ganho em termos de adaptabilidade do processo $^{41}$. Nesse sentido, é possível que as partes venham a adequar os prazos do referido calendário em função da complexidade dos fatos investigados. As mesmas mãos que firmam o pacto dispondo sobre um prazo inicialmente exíguo podem, pelo mesmo consenso, modular esses prazos de modo que se tornem mais longos à medida em que assim se faça necessário ${ }^{42}$.

\footnotetext{
${ }^{40}$ Vale destacar o quanto referido por Leonardo Carneiro da Cunha: "Inspirado nas experiências francesa e italiana, o art. 191 do novo CPC apresenta uma das grandes novidades a ser adotada no sistema processual brasileiro: o calendário processual. As partes, juntamente com o juiz, podem calendarizar o procedimento, fixando datas para a realização dos atos processuais, que ficam todos agendados. Trata-se de um negócio processual plurilateral típico, celebrando entre juiz, autor e réu, bem como, se houver, intervenientes. Estabelecido o calendário, dispensa-se a intimação das partes para a prática dos atos processuais que lá foram agendados. Também não é mais necessária qualquer intimação para as audiências cujas datas tiverem sido agendadas no calendário. $\mathrm{O}$ calendário vincula as partes e o juiz. Os prazos neles previstos só podem ser alterados em casos excepcionais, devidamente justificados". CUNHA, Leonardo Carneiro da. Negócios Jurídicos Processuais no Processo Civil Brasileiro. In: CABRAL, Antonio do Passo e NOGUEIRA, Pedro Henrique (Org.). Negócios Processuais. Salvador: Juspodivm , 2015. p. 63.

${ }^{41}$ Sobre o tema, ver LACERDA, Galeno. O código como sistema de adequação legal do processo. Revista do Instituto dos Advogados do Rio Grande do Sul. Edição comemorativa do cinquentenário 1926-1976 (1976): 161-170 e DIDIER JR, Fredie. Sobre dois importantes, e esquecidos princípios do processo: Adequação e adaptabilidade do procedimento. Genesis: Revista de Direito Processual Civil. vol. 21 (2001): 530-541.

${ }^{42}$ Comentando o art. 359, $\S 8^{\circ}$, anota Luís Eduardo Simardi Fernandes: “ (...) para que não haja prejuízo à qualidade do trabalho pericial, o estabelecimento de calendário pelo juiz não pode impedir que, em momento posterior, havendo justificativa para isso, ele o altere. Evidentemente, melhor obter um trabalho completo e de alto nível, ainda que se empregue um pouco mais de tempo, do que um trabalho incompleto e de qualidade insatisfatória, feito no prazo inicialmente estabelecido" (in WAMBIER, Teresa Arruda Alvim, DIDIER JR, Fredie, TALAMINI, Eduardo e DANTAS, Bruno (org.). Breves Comentários ao Novo Código de Processo Civil. Op. cit.. p. 975)
} 
Revista Eletrônica de Direito Processual - REDP.

Rio de Janeiro. Ano 11. Volume 18. Número 1. Janeiro a Abril de 2017

Periódico Quadrimestral da Pós-Graduação Stricto Sensu em Direito Processual da UERJ

Patrono: José Carlos Barbosa Moreira. ISSN 1982-7636. pp. 302-324

www.redp.uerj.br

\section{Conclusão}

A construção de um Direito Processual Civil idôneo a atender aos resultados almejados pelo texto constitucional passa pela leitura criteriosa do trabalho desenvolvido pelo legislador. No âmbito da regulamentação da atividade de instrução, o que se vê é a necessidade de atenção constante ao interpretar a linguagem veiculada na lei, a fim de que a mesma possa ganhar um significado consentâneo com o direito fundamental à prova.

De toda sorte, tem-se que é inegável que o sistema jurídico processual, como fruto da inteligência do aplicador das normas jurídicas que dele fazem parte, não é um dado, mas, antes, é resultado de uma construção constante, e não é diferente no que se refere ao regime jurídico aplicável à atividade de instrução no âmbito cível. Impõe-se sempre a necessidade de questionar em que medida certas interpretações propostas para o texto da lei são realmente comprometidas com os resultados almejados à luz do influxo do direito fundamental à prova, que serve como baliza para que se possa identificar o acerto ou o erro nas conclusões alcançadas.

\section{REFERÊNCIAS BIBLIOGRÁFICAS.}

ABELHA RODRIGUES, Marcelo (in WAMBIER, Teresa Arruda Alvim, DIDIER JR, Fredie, TALAMINI, Eduardo e DANTAS, Bruno (org.). Breves Comentários ao Novo Código de Processo Civil.

AMARAL, Guilherme Rizzo. Comentários às Alterações do Novo CPC. Revista dos Tribunais: São Paulo, 2015.

ASSIS, Araken de. Processo Civil Brasileiro V. II, tomo II. Revista dos Tribunais: São Paulo, 2015.

ÁVILA, Humberto. Teoria dos Princípios - da Definição à Aplicação dos Princípios Jurídicos. $13^{\text {a }}$ ed. São Paulo: Malheiros, 2012

CABRAL, Antonio do Passo, CRAMER, Ronaldo. Comentários ao Novo Código de Processo Civil. Forense: Rio de Janeiro, 2015.

CALAMANDREI, Piero. Verità e Verosimiglianza Nel Proceso Civile. Rivista di diritto processuale, vol. 10, n. 1, 1955

CARNEIRO DA CUNHA, Leonardo. Negócios Jurídicos Processuais no Processo Civil Brasileiro. Civil-Negócios Processuais. CABRAL, Antônio do Passo, NOGUEIRA, Pedro Henrique (Org). Juspodivm: Salvador, 2015. 
Revista Eletrônica de Direito Processual - REDP.

Rio de Janeiro. Ano 11. Volume 18. Número 1. Janeiro a Abril de 2017

Periódico Quadrimestral da Pós-Graduação Stricto Sensu em Direito Processual da UERJ

Patrono: José Carlos Barbosa Moreira. ISSN 1982-7636. pp. 302-324

www.redp.uerj.br

CAVALlONE, Bruno. In difesa della veriphobia: considerazioni amichevolmente polemiche su un libro recente di Michele Taruffo. Rivista Di Diritto Processuale, , vol. 65 , n. 1,2010

CHEBATT, Thiago Fernandes, RAVAGNANI, Giovani dos Santos. Considerações Sobre a Prova Testemunhal no Novo Código de Processo Civil. In: MACÊDO, Lucas Buril de, PEIXOTO, Ravi e FREIRE, Alexandre (Org.). Processo de Conhecimento Provas. Salvador: Juspodivm, 2015.

DAVID, Rene e JAUFFRET-SPINOSI, Camille. Los grandes sistemas jurídicos contemporáneos. México: Instituto de Investigaciones Jurídicas, 2010.

DELFINO, Lúcio, LOPES, Ziel Ferreira. A expulsão do Livre Convencimento Motivado do Novo CPC: porque a razão está com os hermeneutas? In: MACÊDO, Lucas Buril de, PEIXOTO, Ravi e FREIRE, Alexandre (Org.). Processo de Conhecimento - Provas. Salvador: Juspodivm, 2015.

DIDIER JR, Fredie. Princípio do Respeito ao autorregramento da Vontade no Processo Civil - Negócios Processuais. CABRAL, Antonio do Passo, NOGUEIRA Pedro Henrique (Org). Juspodivm: Salvador, 2015.

DIDIER JR, Fredie, BRAGA, Paulo Sarna, de Oliveira, Rafael Alexandria. Curso de Direito Processual Civil. V. II, 10 a ed, Juspodivm: Salvador, 2015.

DIDIER JR, Fredie. Sobre dois importantes, e esquecidos, principios do processo: Adequacao e adaptabilidade do procedimento. Genesis: Revista de Direito Processual Civil. vol. 21 (2001).

ECHANDÍA, Hernando Devis. Compendio de la Prueba Judicial, Tomo I. Aguilar: Buenos Aires, 1981.

FERNANDES CHEBATT, Thiago, SANTOS RAVAGNANI, Giovani dos. Processo de Conhecimento - Provas. Considerações Sobre a Prova Testemunhal no Novo Código de Processo Civil. MACÊDO Lucas Buril de, PEIXOTO, Ravi, FREIRE Alexandre (Org). Juspodivm: Salvador, 2015.

FURNO, Carlo. Contributo Alla Teoria Della Prova Legale. Padova: Cedam, 1940

GAJARDONI, Fernando da Fonseca. O Livre Convencimento Motivado Não Acabou no Novo CPC. Em: <http://jota.info/o-livre-convencimento-motivado-nao-acabou-nonovo-cpc>. 
Revista Eletrônica de Direito Processual - REDP.

Rio de Janeiro. Ano 11. Volume 18. Número 1. Janeiro a Abril de 2017

Periódico Quadrimestral da Pós-Graduação Stricto Sensu em Direito Processual da UERJ

Patrono: José Carlos Barbosa Moreira. ISSN 1982-7636. pp. 302-324

www.redp.uerj.br

GODINHO, Robson Renault. A Possibilidade de Negócios Jurídicos Processuais Atípicos em Matéria Probatória. - Negócios Processuais. CABRAL, Antonio do Passo, Nogueira PEDRO HENRIQUE (Org). Juspodivm: Salvador, 2015.

HAACK, Susan. Evidence Matters - Science, Proof and Truth in the Law. Cambridge, 2015.

LACERDA, Galeno. O Código Como Sistema de Adequação Legal do Processo. Revista do Instituto dos Advogados do Rio Grande do Sul. Edição comemorativa do cinquentenário 1926-1976 (1976).

LESSONA, Carlos. Teoria General de la Prueba en Derecho Civil. T: I. Trad. Enrique Aguilera de Paz. Instituto Editorial Reus: Madrid, 1957.

LOUGHLIN, Paula e GERLIS, Stephen. Civil Procedure. $2^{\mathrm{a}}$ ed. Londres: Cavendish Publishing, 2004.

MARINONI, Luiz Guilherme, CRUZ ARENHART, Sergio. Comentários ao Código de Processo Civil. São Paulo: Revista dos Tribunais, 2005.

MARINONI, Luiz Guilherme, ARENHART, Sérgio Cruz. Prova e Convicção. $3^{\mathrm{a}}$ ed. São Paulo: Revista dos Tribunais, 2015.

MEDINA, José Miguel Garcia. Novo Código de Processo Civil Comentado. Revista dos Tribunais: São Paulo, 2015.

MITIDIERO, Daniel. Colaboração no Processo Civil. São Paulo: Revista dos Tribunais, 2009.

PICCININNI, Leo. Le Recenti Riforme Della Giustizia Civile Italiana Tra Esigenze Di Semplificazione, Accelerazione Ed Effettività Della Tutela. In: MARTÍN, Agustín Jesús Pérez-Cruz e BAAMONDE, Xulio Ferreiro (org.). Los retos del Poder Judicial ante la sociedad globalizada. Actas del IV Congreso Gallego de Derecho Procesal (I Internacional) A Coruña, 2 y 3 de junio de 2011. A Coruña: Universidade, 2012.

PICOZZA, Elisa. Il Calendario del Processo. Rivista di Diritto Processuale, v. 64, n. 6, 2009.

PONTES DE MIRANDA, Francisco Cavalcanti. Tratado de Direito Privado. Tomo III. Borsoi: Rio de Janeiro, 1958.

RANGEL, Rui Manuel de Freitas. O Ônus da Prova no Processo Civil. Coimbra: Almedina, 2000 .

REICHELT, Luis Alberto. A Prova no Direito Processual Civil. Porto Alegre: Livraria do Advogado, 2009. 
Revista Eletrônica de Direito Processual - REDP.

Rio de Janeiro. Ano 11. Volume 18. Número 1. Janeiro a Abril de 2017

Periódico Quadrimestral da Pós-Graduação Stricto Sensu em Direito Processual da UERJ

Patrono: José Carlos Barbosa Moreira. ISSN 1982-7636. pp. 302-324

www.redp.uerj.br

ROSENBERG, Leo. Derecho Procesal Civil, Tomo II. EJEA: Buenos Aires, 1955.

SARLET, Ingo Wolfgang; MARINONI, Luiz Guilherme; MITIDIERO, Daniel. Curso de Direito Constitucional. São Paulo: Revista dos Tribunais, 2012.

STRECK, Lênio Luiz. As Provas e o Novo CPC: a extinção do Poder de Livre Convencimento. IN: FELIX JOBIM, Marco, SANTOS FERREIRA, William (org.)

Direito Probatório. $2^{\mathrm{a}}$ ed.,. Salvador: Juspodivm, 2015.

TARUFFO, Michele. Contro la veriphobia. Osservazione sparsa in risposta a Bruno Cavallone. Rivista Di Diritto Processuale, v. 65, n. 5, 2010

TARUFFO, Michele. La Prova dei Fatti Giuridici. Milano: Giufrè, 1992.

TARUFFO, Michele. La Motivazione Della Sentenza Civile. Cedam: Padova, 1975.

TARUFFO, Michele. Processo Civil Comparado: Ensaios - Verdade e Processo. Marcial Pons: São Paulo, 2013.

WAMBIER, Teresa Arruda Alvim, DIDIER JR, Fredie, TALAMINI, Eduardo e DANTAS, Bruno (org.). Breves Comentários ao Novo Código de Processo Civil. São Paulo: Revista dos Tribunais, 2015. 